Report

\title{
Contemporary activities of Toxicologic Pathology Societies
}

\author{
Robert R. Maronpot ${ }^{1}$ and Maria L.Z. Dagli² \\ ${ }^{1}$ Maronpot Consulting LLC, Raleigh, NC, USA \\ ${ }^{2}$ Department of Pathology, School of Veterinary Medicine and Animal Science, University of Sao Paulo, Sao Paulo, SP, Brazil
}

\begin{abstract}
Educational activities and training opportunities in toxicologic pathology are major goals of 9 formally established Toxicologic Pathology Societies and the International Academy of Toxicologic Pathology. Some Toxicologic Pathology Societies have examination-based certification programs while others accept certification or registration by veterinary pathology organizations including the American College of Veterinary Pathologists, the European College of Veterinary Pathologists. We summarize here the membership numbers and current activities of formally established Toxicologic Pathology Socities. (DOI: 10.1293/tox.2019-0000; J Toxicol Pathol 2020; 33: 57-63)
\end{abstract}

Key words: Toxicologic Pathology Societies, educational activities, certification programs, toxicologic pathology, training, certification

\section{Introduction}

The World Toxicologic Pathology Congress (WTPC) held in Sao Paulo in April 2018 provided an opportunity for toxicologic pathology leaders to compare and discuss their respective toxicologic pathology society's educational programs and efforts. The participants \& specific society members (see Table 1) were invited to address three questions: 1. What is each society/organization doing for their immediate membership; free lectures/symposia, webinars, symposia requiring payment, externships, cost for student to attend annual meetings, etc.?

2. What is each society/organization doing for global education?

3. What is the position of each society/organization on accreditation/official recognition of toxicologic pathology credentials?

\section{BSTP (www.bstp.org.uk)}

The British Society of Toxicological Pathology (BSTP) was established in 1985 and holds a 2-day annual scientific meeting (including the annual general meeting) typically in November, and recently using a hotel venue within a reasonable distance of an international airport. In recent years this meeting has been a collaborative event with other societies.

Published online in J-STAGE: 14 November 2019

(C)2020 The Japanese Society of Toxicologic Pathology

This is an open-access article distributed under the terms of the Creative Commons Attribution Non-Commercial No Derivatives (c) $\bigoplus_{\mathrm{BY}} \bigoplus_{\mathrm{ND}}$ creativecommons.org/licenses/by-nc-nd/4.0/).
In addition to providing continued professional development (CPD) opportunities, these meetings provide a unique opportunity for interaction and networking between scientists from a wide range of disciplines.

There are 228 active BSTP members. Membership is open to anyone with an interest in the fields of toxicologic and experimental pathology.

The main focus of the BSTP is the organization of Continuing Education Symposia (CES) which offer high quality CPD opportunities for toxicological and discovery pathologists (and other scientists working with animal models), clinical pathologists and toxicologists as well as nonclinical regulatory scientists. The CES mainly focuses on specific organ systems. There are 2 different organ specific CES each year (typically in March and July), so that over the next 6-7 years, the complete set of 15 CES covering all major organ systems will have been presented. There is an attendance fee for each CES and the venue is typically at an academic institution in the United Kingdom. Each CES comprises 3 full days of presentations (Tuesday-Thursday) and now involves reviewing and discussion of digital images rather than the microscope evaluation of glass slides. The BSTP CES are open to interested individuals from all countries. There is no examination associated with BSTP CES, although in conjunction with the CES, as a separate event, the BSTP does provide a mock examination for individuals preparing for certification.

At each CES, the BSTP offers one free place to individuals working within an "early career" environment, for example, stipendiary students/researchers studying/working within a relevant scientific field, veterinary pathology residents and professional trainee pathologists working towards a professional qualification or gaining more experi- 
Table 1. Toxicologic Pathology Organizations

\begin{tabular}{lccl}
\hline Society & Year Established & Active Membership & Acknowledgement of contributions \\
\hline BSTP & 1985 & 228 & John Foster, BSTP Secretariat \\
ESTP & 2002 & 300 & Sibylle Groeters \& Anna-Lena Frisk \\
IATP & 1999 & 102 & Darlene Dixon \\
JSTP & 1984 & 969 & Taki Harada \& Dai Nakae \\
KSTP & 2002 & 150 & Beom Seok Han \& Jae-Hak Park \\
LASTEP & 2005 & 100 & Maria Dagli \& J.L V. Camargo \\
NLSTP & 1988 & 19 & Joost Lensen \\
SFPT & 2003 & 90 & Flavia Pasello \& Erio Barale \\
STP & 1971 & 1,325 & Wanda Haschek \& Matt Price \\
STP-I & 2004 & 259 & Venkatesha Udupa \\
\hline
\end{tabular}

BSTP $=$ British Society of Toxicologic Pathology. ESTP $=$ European Society of Toxicologic Pathology. IATP = International Academy of Toxicologic Pathology. JSTP = Japanese Society of Toxicologic Pathology. KSTP $=$ Korean Society of Toxicologic Pathology. LASTEP $=$ Latin American Society of Toxicologic and Experimental Pathology. NLSTP $=$ Netherlands Society of Toxicologic Pathology. SFPT $=$ French Society of Toxicologic Pathology. STP = Society of Toxicologic Pathology (United States). STP-I = Society of Toxicologic Pathology-India (Two Chinese toxicologic pathology societies are in early stages of development).

ence within the field of toxicological pathology. For the Annual Scientific Meeting, the BSTP aims to offer 5 free places using the same criteria. Additionally, for all BSTP events, reduced registration fees rates are available to individuals working within an "early career" environment. The BSTP is also able to award (on application) a bursary to help cover costs for travel and attendance at scientific meetings.

The BSTP occasionally offers other one-day seminars and in conjunction with the STP, the BSTP have a webinar program with the aim of providing 5 webinars per year. The BSTP is still working to establish a mentorship program where more experienced pathologists can work one-on-one with trainees and junior professionals. The BSTP also maintains an industry supported digital archive (EPSR) of toxicologic pathology images that is available to its membership. The BSTP, STP, and ESTP share responsibility for the journal Toxicologic Pathology where published manuscripts are freely available to members of each society.

Although the BSTP does not have a formal toxicologic pathology certification program, support and guidance for those seeking certification is available with information provided on the BSTP websit. There are 8 veterinary schools in UK plus more than 90 veterinary schools and veterinary faculties in Europe that provide a source for new toxicologic pathologists.

\section{ESTP (www.eurotoxpath.org)}

The European Society of Toxicologic Pathology (ESTP) was established in 2002 by several European Societies (German, Italian, and Nordic countries) while others joined but maintained their national activities (SFTP, NLSTP) or came in later but without a separate toxicologic pathology division (part of the Hungarian Society of Toxicology).

The ESTP hosts a 3-day scientific meeting typically in September each year. Every third year, the annual scientific meeting is a joint meeting with the ECVP and ESVP, called
"Cutting Edge Pathology" and also has joint meetings with other scientific societies (e.g. European Teratology Society, IATP).There are over 300 active members of the ESTP, representing 25 countries and full membership is open to anyone working full time in the field of toxicologic pathology.

The annual scientific meeting is composed of key lectures and oral presentations by invited speakers on a special topic, a poster exhibition, and interactive case presentations. In addition, the ESTP sponsors an annual international expert workshop with limited attendance by invitation on a topic of contemporary relevance in toxicologic pathology. Presentations from these international expert workshops are available to ESTP members with access via the ESTP website and are published in a conclusive paper. In association with the ESTP Pathology 2.0 committee, periodic webinars on relevant toxicologic pathology topics are available to society members. The ESTP website provides interesting cases from the field of toxicologic pathology for its membership and members have free access to diagnostic nomenclature and images at www.goRENI.org. In support of younger toxicologic pathologists, the ESTP sponsors annual publication and thesis awards and is responsible for selecting recipients. Awardees gain a money award and one-year free membership. ESTP members actively participate in international working groups and work closely with other societies of toxicologic pathology. The ESTP, STP, and BSTP share responsibility for the journal Toxicologic Pathology where published manuscripts are freely available to members of each society.

To attract young pathologists to the field of Toxicologic Pathology, the ESTP, together with European pharmaceutical and (agro-)chemical companies as well as CRO's, initiated a program for students and post-graduate students. Within this program, the students get the possibility to gain insight into the daily work of toxicologic pathologists in different environments.

The ESTP does not have a formal toxicologic patholo- 
gy certification program. However, the Pathology PhD Program of several Universities throughout Europe (e.g. Hannover Veterinary School) are supported with seminars and lectures. Moreover, the annual seminar "Classic Examples of Toxicologic Pathology" that has been held for more than 25 years in Hannover is open for professionals and students. The ESTP maintains an active website with information on certification programs. There is a high demand for certified toxicologic pathologists in Europe and greater than 90 veterinary schools or veterinary faculties provide a potential source for new toxicologic pathologists.

\section{IATP (www.iatpfellow.org)}

The International Academy of Toxicologic Pathology (IATP) was established in 1999 by the International Federation of Societies of Toxicologic Pathology. Becoming an IATP Fellow is a formal recognition of competency in toxicologic pathology based on experience and scientific contributions. Accreditation as an IATP Fellow is the highest level of global recognition of competency in toxicologic pathology. Currently there are 110 accredited IATP Fellows representing members of each of 8 established toxicologic pathology societies. Criteria for accreditation are provided on the IATP website. Applications to become an IATP Fellow are reviewed by an international Accreditation Committee consisting of 9 IATP Fellows.

The IATP sponsors half-day symposia and lectures in collaboration with toxicologic pathology societies in addition to conducting webinars. IATP participation in global educational events enables IATP Fellows to give something back to the toxicologic pathology community. Over the past 11 years the IATP has provided over 35 student trainee awards at different toxicologic pathology society annual meetings.

\section{JSTP (www.japantoxpath.org/en/)}

The Japanese Society of Toxicologic Pathology (JSTP) was established in 1984 and currently has 949 active members. Full membership is open to all based on academic background with approval by the JSTP Executive Board. Student membership is open to those who are majoring in toxicologic pathology or related fields and are typically enrolled in academic degree programs. A 2-day annual scientific meeting is typically held in late January. Seventeen Japanese veterinary schools, 81 medical schools, and schools of other related fields (e.g., pharmacology and science) provide a source for new toxicologic pathologists.

An annual slide conference is held the day before the annual scientific meeting and the topics covered are rotated based on organ systems. Additionally, the JSTP offers a continuing education (CE) course in November each year. A fee is charged for both the slide conference and the CE course and documents related to these events are available to registered participants and 3 years later to all JSTP members. Meeting Chairperson Awards are provided during the an- nual scientific meetings each year chiefly based on poster presentations of young members. In addition, there are an annual IATP Charles Capen trainee award, an IATP food safety award, and JTP Scientific Awards. In 2017 the JSTP completed a Japanese language 824-page text book with color photomicrographs on Toxicologic Pathology that is available for purchase. The Journal of Toxicologic Pathology (JTP), established in 1988, is the official journal of the JSTP. All published articles are freely available. The JSTP maintains an active website.

The JSTP offers a certification program in toxicologic pathology. The program is given in Japanese and/or English and consists of a written, macro-, and microscopic examination available to candidates who have 5 years of membership, toxicologic pathology experience and activity, and at least one publication in JTP. Currently there are 381 toxicologic pathologists (D.JSTP) certified by the JSTP.

\section{KSTP (https://www.ksotp.or.kr)}

The KSTP was established in 2002 and 23 medical and veterinary pathologists who were actively engaged in evaluation of toxicological tests became the first members of the KSTP. KSTP currently has 150 active members plus 30 student members and 20 other members. There are two scientific meetings per year each lasting 2 days with approximately 100 attendees. Student poster awards are presented at the annual meetings. Additionally, the KSTP sponsors regional scientific meetings, including joint meetings with other scientific societies such as Korean Society of Veterinary Science.

In 2008, KSTP started formal education programs for certification of toxicologic pathologists and certifies the eligibility of applicant candidates. Presently there are 42 certified toxicologic pathologists in KSTP.

Criteria for eligibility for certification in toxicologic pathology include a medical or veterinary doctoral degree, passing examination by a certifying committee, and 3 or more years of relevant work experience after obtaining a master's degree in pathology or laboratory pathology. Documents for eligibility include a master thesis, five or more pathology- related presentations or pathology reports (subacute toxicity test), and/or recommendation from two toxicologic pathologists. Certification examination includes a written test based on the Handbook of Toxicologic Pathology and a practical examination based on figures from INHAND publications. Toxicologic pathologists can maintain their certification for a period (6 years). Criteria for maintaining certification include some of the following: attendance and presentation at conferences and workshops, attendance at toxicologic pathology slide conferences, attendance and presentation at official toxicologic pathology society annual meetings, publication of toxicologic pathology related manuscripts, serving on journal editorial boards, authoring toxicity/carcinogenicity study reports, and serving as executive members of toxicology- related scientific boards of directors. 


\section{LASTEP}

The Latin American Society of Toxicologic and Experimental Pathology (LASTEP) was founded in 2005. Its original name was Latin American Society of Toxicologic Pathology, LASTP, but it was changed to LASTEP in 2014 in order to attract the experimental pathology community. LASTEP currently has 100 members and 6 honorary members. Although headquartered in Brazil, LASTEP has members from 5 other South American countries (Argentina, Chile, Colombia, Peru, Venezuela).

The demand for certified toxicologic pathologists in South America is low, and there are no formal toxicologic pathology training programs yet. A potential source for toxicologic pathologists in Latin America would be from the many schools of veterinary medicine (for example, 407 in Brazil). A formal veterinary pathology certification is at present provided by the Brazilian Association of Veterinary Pathology (Associação Brasileira de Patologia Veterinária, ABPV). This Association has been authorized by the Federal Council of Veterinary Medicine (Conselho Federal de Medicina Veterinária, CFMV) of Brazil to provide an examination for accreditation.

LASTEP organizes its meeting every 2 years, in general in the month of April. In 2018, in conjunction with IFSTP, LASTEP organized the World Toxicologic Pathology Congress, WTPC, in the city of Sao Paulo, state of Sao Paulo, Brazil, when 144 attendees registered and 100 posters were submitted.

\section{NLSTP}

In 1988 the Dutch Registration Committee for Laboratory Animal Pathologists/Toxicologic Pathologists (CRP/ TP: Commissie Registratie Proefdierpathologen/Toxicologische Pathologen) was founded. This Committee falls under the auspices of the Dutch Society of Pathology (NVVP; Nederlandse Vereniging voor Pathologie) and the Royal Dutch Society for Veterinary Medicine (KNMvD; Koninklijke Nederlandse Maatschappij voor Diergeneeskunde) and is responsible for the registration, the re-registration (every 5 years) and the monitoring of training of candidate laboratory animal pathologists and toxicologic pathologists. The training of toxicologic pathologist is a joint responsibility of Veterinary Pathologists and registered Toxicologic Pathologists.

Currently there are $19 \mathrm{CRP} / \mathrm{TP}$ registered laboratory animal/toxicologic pathologists, with more (non-CRP/TP) members of the toxicologic and veterinary pathology sections of the NVVP and the Dutch Society of Toxicology (NVT: Nederlandse Vereniging voor Toxicologie).

The NLSTP two-day annual scientific meeting typically occurs in June in conjunction with the NVT with a three-day meeting in conjunction with the NVVP in March/ April. The attendance at these meetings is approximately 150 participants. Student members enjoy a reduced registration fee and there are study poster awards at the meetings.
The NLSTP aims to have a comparative pathology slide seminary with the NVVP at least once each year with human and veterinary cases presented.

There is an annual one-week postgraduate education in toxicology course (PET course) covering toxicologic pathology and pathobiology. In addition, the topic "toxicologic pathology" is provided as part of the elective course "veterinary toxicology" in the bachelor program at the Faculty of Veterinary Medicine, University of Utrecht. The NLSTP occasionally co-organizes courses with other societies.

There is an active certification in toxicologic pathology (CRP/TP) for individuals with an advanced degree and at least 4 years of relevant experience. Oral and written examinations may be included for parts of the certification program. Candidates are typically trained on-the-job for 4 years under the tutorship of an experienced and registered toxicologic pathologist. During the training period, a required, tailor-made program must be fulfilled. The Registration committee keeps track of training progress by regular review. Alternatively, a candidate may choose to attend the ECVP examination, followed by a 2-year on-the-job training.

The local demand for certified toxicologic pathologists in The Netherlands is low. One veterinary school and five biomedical universities (out of a total of 8 medical universities) may serve as a source of toxicologic pathologists.

\section{SFPT (https://toxpathfrance.org)}

The Société Française de Pathologie Toxicologique (SFPT, or French Society of Toxicologic Pathology) is a non-profit organization founded in March 2003, with approximately 90 members, mainly based in France but also in Canada, Belgium, Switzerland and the U.K. The French STP resulted from the fusion of the SFAT (the French Society of Toxicologic Anatomic Pathologists, founded in 1981) and the AAEOCESHHAPAL (the French association of the organizers and fellows of the program in histology, hematology and anatomic pathology of lab animals, founded in 1978).

The members of the French STP are veterinary pathologists dedicated to the integration of toxicologic pathology into medical and veterinary research, human and environmental risk assessment of pharmaceuticals, chemicals, agrochemicals, biocides, biomaterials, etc. The objectives of the French STP are to promote the development of toxicologic pathology in France by supporting the training of young pathologists and continuing education programs, interacting with sister societies of other countries and supporting the activities of the European STP. Meetings to promote contact among members and discussions on scientific topics are held on an annual basis.

The French STP actively supports the French 3-year post-graduate educational training in veterinary anatomic pathology (DESV, i.e. Diplôme d'Études Spécialisées Vétérinaires en Anatomie Pathologique Vétérinaire, created in 1987) which is the French residency program recognized by 
the European College of Veterinary Pathologists (ECVP). The DESV is a training program preparing veterinarians to become specialists in Veterinary Pathology. This post-graduate educational program, created in 1987, is co-organized by the Pathology Departments of the 4 French Veterinary Schools (Lyon, Maisons-Alfort, Nantes and Toulouse) and directed by a Coordination Board (COF) comprising 6 professors nominated by the 4 veterinary schools and 6 "external" pathologists representing the non-academic profession (e.g. pharmaceutical industry, biomedical research and veterinary diagnostic labs). The program is open to individuals holding a French DVM degree, or an equivalent professional degree in veterinary medicine obtained in a European Union country. The DESV students are full-time residents in one of the 4 veterinary schools and follow theoretical and practical training in all fields of veterinary pathology (small and large domestic animals, laboratory animals, poultry, fish, wild and exotic animals). A large number of necropsy cases (around 400 per year), classical examples of slides or photomicrographs and regular seminars are available for the training.

About 20 week-long seminars on general and special pathology (6-7 weeks per year) are organized by the veterinary schools. In addition, during the 3-year program, the DESV students must register for 3 training externships aimed to provide knowledge on basic morphological techniques ( 2 months) and toxicologic pathology ( 2 months) and to enroll the students in a research program (7-month in duration) in either pharmaceutical, agrochemical, cosmetic industry, biomedical research or veterinary diagnostics. DESV students have an examination at the end of each year and must present the results of their research project at the end of their training. The DESV diplomates are finally expected to be able to carry out a comprehensive evaluation of all aspects of veterinary pathology and clinical pathology.

DESV diplomates currently hold high positions in pharmaceutical and agrochemical companies, private veterinary pathology laboratories, pathology departments of veterinary schools and biomedical research laboratories not only in France but also in other European or North American countries. At the end of the 3-year training program, many DESV diplomates generally embark on a 6-month dedicated intensive training aimed to prepare for the ECVP exam.

Members of the French STP work closely with the DESV by giving lectures, providing material/slides from laboratory animals, sponsoring training courses for the new generation of pathologists and helping these students to find externship in the industry.

\section{STP (www.toxpath.org)}

Established in 1971, the Society of Toxicologic Pathology (STP) currently has 1,325 active members from 28 countries around the world, including 1,000 Full Members and more than 150 Student members. Additionally, the STP has Associate, Emeritus and Honorary membership catego- ries. STP Membership is conferred by a majority vote of the Executive Committee based on the recommendations of the Membership Committee. The STP Annual Symposium is held in June each year, starting on a Saturday with the always informative and highly interactive National Toxicology Program (NTP) Symposium "Pathology Potpourri," half-day fee-based CE courses on Sunday, and a formal meeting of six sessions from Monday morning until Thursday afternoon. Between 500-600 attendees typically attend the annual meeting, including student members who receive free registration. Multiple awards and scholarships are provided for students/trainees to help offset the cost of attending the STP Annual Symposium and STP Modular Courses.

In addition to $\mathrm{CE}$ courses at the annual scientific meeting, the STP sponsors a number of one-day regional courses, typically on a focused topic of contemporary interest. Additionally, STP hosts a 3-day modular course that is focused on an organ system and is suitable for both experienced and novice pathologists. Another source of educational material includes an active webinar program, often in association with sister societies. The STP strongly encourages an interest in toxicologic pathology by providing freely available webinars and lectures and periodically co-hosting a joint annual meeting with the American College of Veterinary Pathologists. The STP has a career development and outreach effort with a half-day course and lunchtime panel discussions. With respect to global outreach, the STP has a global scholar outreach award to cover travel to sister professional societies and provides jointly sponsored webinars each year with toxicology and sister toxicologic pathology societies. The journal Toxicologic Pathology is the Official Journal of the BSTP, ESTP, and STP with both print subscriptions and electronic access available to members of each society. The Scientific and Regulatory Policy Committee (SRPC) of the STP is tasked with providing scientific leadership on common or emerging global toxicologic pathology issues within the drug, chemical, and medical device industries in order to promote appropriate industry practices and good regulatory policies. Specific articles sponsored by SRPC are identified in Toxicologic Pathology to benefit all parties with interest in industry practices. Additionally, the STP has an active effort in publishing best practices in toxicologic pathology; access to these is freely available on the STP website. Further support of global education is provided by the Short Education Webinar Series that can be accessed at any time from the STP website.

The STP does not offer a certification program in toxicologic pathology nor does it endorse an international accreditation of toxicologic pathologists. STP membership consists of veterinary and medical pathologists, toxicologists, and other professionals. Many STP members are certified by the ACVP, ECVP or JSTP. There are 30 schools of veterinary medicine and 179 medical schools that are a potential source for future toxicologic pathologists in the United States. 


\section{STP-I (www.toxpathindia.com)}

The STP-I was established in 2004 and currently has 259 full members and 15 student members. Full or Primary Membership requires a graduate degree in pathology and active practice in toxicologic pathology. Associate Membership is available for those with graduate degrees in pathology, pharmacology or toxicology but without active practice of toxicologic pathology. Student membership is available for those working on a graduate degree or PhD scholars.

STP-I has a 2.5-day annual meeting usually held in late October 2018 with international speakers and over 200 attendees. Student poster awards and a Charles Capen trainee award are given at the annual meeting. In addition to annual meetings, formal career development and mentoring is provided for trainees in the form of at least 2 workshops every year. STP-I has an informative website and sponsors freely available webinars through IATP.

The Indian Board of Toxicologic Pathology (IBTP), established in 2011, is an affiliate of STPI, certifies toxicologic pathologists via written and practical examination. Candidates for certification must have at least 5 years of relevant experience and an MVSc or MD degree as a minimal educational requirement. The local demand for certified toxicologic pathologists is high in India. Up to 12 local veterinary schools are a source for toxicologic pathologists. As on December 2018, IBTP has 44 Diplomates.

\section{Discussion}

An early attempt to coordinate the missions and activities of the various societies of toxicologic pathology lead to the formation of the IFSTP in 1989. That organization was established to provide a global perspective relative to the discipline of toxicologic pathology to build, integrate, and set standards in toxicologic pathology in addition to fostering the establishment of new toxicologic pathology societies, promoting educational activities and representing member societies in the regulatory environment. IFSTP member societies included memberships representing Japan, China, Latin America, The Netherlands, India, Europe, Korea, United Kingdom, Italy, and the United States with initial funding by contributions from member societies based on their number of active members.

One of the early discussions among IFSTP members was to consider the establishment of a global certification system for competency of practitioners of toxicologic pathology. In thinking about how certification might be managed, the IFSTP created the IATP, a daughter organization, established in 1999 to identify and acknowledge leaders and experts in toxicologic pathology based on educational credentials and professional accomplishments. While early discussion centered on IATP Fellows playing a significant role in a global certification process for toxicologic pathologists, the small number of IATP Fellows made their participation in a global certification process impractical and subsequent- ly IATP began to operationally function independently from IFSTP with a focus on educational activities. In the meantime, IFSTP formulated a detailed plan for global certification of toxicologic pathologists in preparation for discussion at their meeting in Puerto Rico in June 2007. Details regarding the IFSTP proposal were provided in 2007 and 2008 in white papers and subsequent publications in three relevant toxicologic pathology journals ${ }^{1,2}$. In 2009 the STP Town Hall meeting was devoted to a debate on the desirability of an international mechanism for recognizing qualified toxicologic pathologists ${ }^{3}$. The majority of participants were against the IFSTP proposal but favored the concept of global recognition based on credential review and a "best practices" approach dealing with educational and work experience and rigorous peer review for entry-level proficiency in toxicologic pathology 4,5

While ongoing discussions related to global certification of toxicologic pathologists were underway, individual societies matured and found they could proceed with their missions without needing the oversight of an IFSTP confederation and raised some concern about annual dues for membership in IFSTP. In an effort to continue its role as a confederation of societies of toxicologic pathology, by 2013 the IFSTP ceased collecting membership fees. Nevertheless, for different reasons the more established toxicologic pathology societies decided to no longer remain a part of the IFSTP confederation and formally withdrew their IFSTP membership. As a final activity, the IFSTP provided partial support for a World Toxicologic Pathology Congress held in Sao Paulo, Brazil in April 2018. Later in 2018 the IFSTP was formally dissolved and remaining funds were transferred to the IATP with the stipulation those funds be used exclusively for educational purposes. With regard to certification in toxicologic pathology, the JSTP, NLSTP, and STP-I have established their own internal certification processes. The STP, ESTP, and BSTP do not have a formal toxicologic pathology certification program and rely on an examinationbased board certification in veterinary pathology provided by the ACVP (US) and ECVP (EU) to identify pathologists with qualifications in toxicologic pathology.

Following the dissolution of IFSTP, starting in 2017 the active toxicologic pathology societies elected to sponsor periodic meetings and associated teleconferences (referred to as Global Presidents Meetings) with the leadership of the various societies in conjunction with annual meetings of the STP, the JSTP and the ESTP. Because of the scheduling of the STP, JSTP and ESTP annual meetings, these joint meeting/teleconferences occur at least three times during a calendar year and allowed for exchange of information and discussion of contemporary challenges in the field of toxicologic pathology. Topics for discussion during these meetings have included the coordinated activities of the International Harmonization of Nomenclature and Diagnostic Criteria (INHAND) efforts 6,7 and addressing requests from regulatory authorities related to diagnostic nomenclature and related submissions for regulatory approval. As is readily 
apparent from these contemporary meetings of the different societal leaderships, an emphasis of fostering education is a common theme, including establishing joint educational seminars and webinars to the benefit of all toxicologic pathology societies. Other sources of related educational activities and teaching material are provided by the C. L. Davis Foundation, the U.S. National Toxicology Program, the Registry of Industrial Toxicology Animal-Data (RITA) and Regional Nomenclature Information System (RENI).

\section{Future Perspectives}

Based on the excellent continuing interactive and collaborative efforts among toxicologic pathology societies related to the INHAND and Standard for the Exchange of Nonclinical Data (SEND) efforts, joint ownership of the journal Toxicologic Pathology among 3 societies (STP, ESTP and BSTP), and discussion of contemporary topics at the Global Presidents Meetings, the need for a more formal confederation of toxicologic pathology societies is currently not apparent. What is apparent is that each of the societies has identified leadership and formulated policies, goals, and operations consistent with regional and local cultural needs. It will be critical that the larger and more established toxicologic pathology societies continue to foster the independence of and collaboration with smaller newly established societies.

\section{Editor's Note}

This article is being published in parallel in Journal of Toxicologic Pathology and Toxicologic Pathology.

Disclosure of Potential Conflicts of Interest: The authors declared no potential conflicts of interest with respect to the research, authorship, and/or publication of this article.

\section{References}

1. Ettlin RA, Bolon B, Pyrah I, Konishi Y, and Black HE. Global recognition of qualified toxicologic pathologists: where we are now and where we need to go. Toxicol Pathol. 36: 753-759. 2008; [Published in parallel in Exp Toxicol Pathol. 60: 1-8. 2008 and J Toxicol Pathol. 20: 267-272. 2007]. [Medline] [CrossRef]

2. Ettlin RA, Bolon B, Pyrah I, Konishi Y, and Black HE. Global recognition of qualified toxicologic pathologists: credential review as a potential route for recognizing the proficiency of pathologists involved in regulatory-type nonclinical studies. Toxicol Pathol. 37: 553-561. 2009; [Published in parallel in Exp Toxicol Pathol. 62: 413-422. 2010 and J Toxicol Pathol. 22: 143-152. 2009]. [Medline] [CrossRef]

3. Bolon B, Ochoa R, and Mann P. STP debate on the desirability of an international mechanism for recognizing qualified toxicologic pathologists. Toxicol Pathol. 37: 992-996. 2009. [Medline] [CrossRef]

4. Bolon B. The World weighs in on optimal toxicologic pathology training practices: it's unanimous! Toxicol Pathol. 39: 294. 2011. [Medline] [CrossRef]

5. Bolon B, Barale-Thomas E, Bradley A, Ettlin RA, Franchi CA, George C, Giusti AM, Hall R, Jacobsen M, Konishi Y, Ledieu D, Morton D, Park JH, Scudamore CL, Tsuda H, Vijayasarathi SK, and Wijnands MV. International recommendations for training future toxicologic pathologists participating in regulatory-type, nonclinical toxicity studies. Exp Toxicol Pathol. 63: 187-195. 2011. [Medline] [CrossRef]

6. Mann PC, Vahle J, Keenan CM, Baker JF, Bradley AE, Goodman DG, Harada T, Herbert R, Kaufmann W, Kellner $\mathrm{R}$, Nolte T, Rittinghausen S, and Tanaka T. International harmonization of toxicologic pathology nomenclature: an overview and review of basic principles. Toxicol Pathol. 40(Suppl): 7S-13S. 2012. [Medline] [CrossRef]

7. Vahle J, Bradley A, Harada T, Herbert R, Kaufmann W, Kellner R, Mann P, Pyrah I, Rittinghausen S, and Tanaka T. The international nomenclature project: an update. Toxicol Pathol. 37: 694-697. 2009. [Medline] [CrossRef] 